\title{
Rare Coexistence of Congenital Adrenal Hyperplasia due to 21-Hydroxylase Deficiency and Turner Syndrome: A Case Report and Brief Literature Review
}

\author{
(D) Isabel Inácio1, (D) Joana Serra-Caetano2, (1) Rita Cardoso², (D) Isabel Dinis², (D) Alice Mirante2 \\ ${ }^{1}$ Centro Hospitalar do Baixo Vouga, Department of Endocrinology, Aveiro, Portugal \\ ${ }^{2}$ Hospital Pediátrico de Coimbra, Department of Paediatric Endocrinology, Diabetes and Growth, Coimbra, Portugal
}

What is already known on this topic?

The combination of Turner syndrome and congenital adrenal hyperplasia ( $\mathrm{CAH})$ is rarely reported in the literature.

What this study adds?

We report a new case of the coexistence of mosaic Turner syndrome and the non-classical form of CAH due to 21 -hydroxylase deficiency, associated with a de novo mutation in the CYP21A2 gene. This case did not present with short stature.

\begin{abstract}
The coexistence of congenital adrenal hyperplasia (CAH) due to 21-hydroxylase deficiency and Turner syndrome (TS) is rare. We report on a 6-year-old Portuguese girl with mosaic TS [45,XO(39)/47, XXX(21)] presenting with premature pubarche at the age of 5 years. Laboratory findings showed elevated 17-hydroxyprogesterone, dehydroepiandrosterone sulfate, androstenedione and total testosterone, and her sex-determining region Y (SRY) was negative. CYP21A2 gene analysis revealed two mutations (c. [844G > T]; [CYP21A2del]), consistent with the non-classical form of CAH. Complete deletion of CYP21A2 allele occurred de novo. At 6 years and 4 months, she presented with accelerated growth velocity and hydrocortisone at a dose of $5 \mathrm{mg} / \mathrm{m}^{2} /$ day was initiated. This case highlights the need to perform global examinations looking for virilization signs in TS patients' follow-ups. It also supports the reported genetic combination of TS and CAH. Therefore, CAH should be kept in mind in TS patients with SRY negative and virilization signs, even in the absence of short stature.
\end{abstract}

Keywords: Adrenal hyperplasia, congenital, Turner syndrome, virilism, karyotyping

\section{Introduction}

Turner syndrome (TS) is a common genetic disorder among young females and it is characterized by infertility, premature ovarian deficiency, short stature and other abnormalities (1). Some patients have the classical monosomy X $(45, \mathrm{X})$ and others have various $45, \mathrm{X}$ mosaicism, including mosaic monosomy $\mathrm{X}$ with a Y-bearing cell line. Virilization occurring in TS patients should prompt a search for the $\mathrm{Y}$ chromosome-bearing cell line, as these individuals are at risk of developing malignant gonadal tumors and they can present with ambiguous genitalia, as with congenital adrenal hyperplasia (CAH) $(2,3)$.

CAH secondary to 21 -hydroxylase $(21-\mathrm{OH})$ deficiency is one of the most common causes for virilization in females. There are three forms: the classic salt-wasting, simple virilising and the non-classical or late-onset, the latter being the most prevalent type (4).

CAH and TS are not very rare diseases, but their combination is rare and may be confounding $(4,5)$. We report on a case of 
TS with coexisting 21-OH deficiency. The second condition was only recognized during follow-up with the evaluation of the patient's puberty signs.

Written informed consent was obtained from the mother.

\section{Case Report}

The patient, known to be a mosaic for TS $[45, \mathrm{XO}(39) / 47, \mathrm{XXX}(21)]$, was diagnosed during amniocentesis and confirmed by postnatal karyotype. She was referred to the Pediatric Endocrinology Department at 20 months of age. She was born at term from the second gestation of a 35-year-old mother. Her birth weight was $2,565 \mathrm{~g}$, her length was $45 \mathrm{~cm}$ and her head circumference was $32.5 \mathrm{~cm}$. The parents were nonconsanguineous. On physical examination, she presented with good general appearance, low posterior hairline, micrognathia, and Tanner stage 1. During follow-up, she had recurrent otitis media. Echocardiography, performed as part of routine investigations in TS patients, revealed no pathology. At 5 years and 8 months, she presented with premature pubarche with three dark thick pubic hairs on the labia majora (Tanner stage 2 pubic hair and Tanner stage 1 breasts). Her height was $109.2 \mathrm{~cm}$ [-0.62 standard deviation (SD)] and her weight was $19.4 \mathrm{~kg}$ (0.09 SD). Initial laboratory findings showed 17-hydroxyprogesterone (17OHP) 18 (0.03-0.9) ng/mL, dehydroepiandrosterone sulfate
$2.76(<0.05-0.57) \mathrm{ug} / \mathrm{mL}$, androstenedione $1.4(0.08-0.5)$ $\mathrm{ng} / \mathrm{mL}$, total testosterone $0.3(<0.03-0.1) \mathrm{ng} / \mathrm{ml}, \mathrm{LH}<0.1$ (0.02-0.3) $\mathrm{mUI} / \mathrm{mL}$ and FSH $2.6(1.0-4.2) \mathrm{mUI} / \mathrm{mL}$ (Table 1). Repeated laboratory work-up confirmed these results (Table 1). Renal and pelvic ultrasonography demonstrated normal kidneys without renal anomalies, and a uterus with dimensions of $2.3 \times 0.7 \times 1.1 \mathrm{~cm}$. Both ovaries were $1.2 \times 0.6$ $\mathrm{cm}$. Analysis of the sex-determining region Y (SRY) gene was negative. Analysis of the CYP21A2 gene revealed the presence of the mild variant c.844G $>\mathrm{T}$ [p.(Val282Leuc)] in hemizygote associated with enzymatic activity of $21-\mathrm{OH}$ of $50 \%$, and the presence of non-functional allele, complete deletion of CYP21A2 (CYP21A2del), associated with null enzymatic activity of $21-\mathrm{OH}$. These results were consistent with a partial deficiency of $21-\mathrm{OH}$ compatible with the nonclassical form of $\mathrm{CAH}$.

Her mother did not present with any of the genetic alterations and her father was a carrier of the mild variant c.844G > T. Her 13-year-old sister had recurrent otitis media and premature pubarche starting at the age of six. Her genetic testing also identified mild variant c.844G > T, associated with the enzymatic activity of $50 \% 21-\mathrm{OH}$, in heterozygosity, in the CYP21A2 gene, although this was not sufficient for a diagnosis of CAH. The sister's last laboratory evaluation showed sodium $137 \quad(136-146) \mathrm{mmol} / \mathrm{L}$, potassium 4.6 (3.5-5.1) mmol/L, 17-OHP 4.19 (0.182.3) $\mathrm{ng} / \mathrm{mL}$, androstenedione $3.4(0.77-2.25) \mathrm{ng} / \mathrm{mL}$, total

\begin{tabular}{|c|c|c|c|}
\hline Age & 5 years and 8 months & 5 years and 10 months & 6 years and 7 months \\
\hline Sodium, $\mathrm{mmol} / \mathrm{L}$ & $139(136-146)$ & & $141(136-146)$ \\
\hline Potassium, $\mathrm{mmol} / \mathrm{L}$ & $4.9(3.5-5.1)$ & & $4.3(3.5-5.1)$ \\
\hline ACTH, pg/mL & & $22(10-60)$ & $20(10-60)$ \\
\hline Cortisol, ug/dL & & $10(3-21)$ & $7.1(3-21)$ \\
\hline Glucose, mg/dL & $82(60-100)$ & & $89(60-100)$ \\
\hline Creatinine, mg/dL & $0.56(0.44-0.64)$ & & \\
\hline $\mathrm{FSH}, \mathrm{mUI} / \mathrm{mL}$ & $2.6(1.0-4.2)$ & $2.7(1.0-4.2)$ & \\
\hline $\mathrm{LH}, \mathrm{mUI} / \mathrm{mL}$ & $<0.1(0.02-0.3)$ & $0.1(0.02-0.3)$ & \\
\hline Estradiol, pg/mL & $<13(5-20)$ & $<13(5-20)$ & \\
\hline $\mathrm{AMH}, \mathrm{ng} / \mathrm{mL}$ & & 0.28 & \\
\hline 17-OH progesterone, ng/mL & $18(0.03-0.9)$ & $17(0.03-0.9)$ & $19(0.03-0.9)$ \\
\hline Total testosterone, $\mathrm{ng} / \mathrm{ml}$ & $0.3(<0.03-0.1)$ & $0.2(<0.03-0.1)$ & \\
\hline Androstenedione, ng/mL & $1.4(0.08-0.5)$ & $1.4(0.08-0.5)$ & \\
\hline $\mathrm{DHEA}-S O_{4}, \mathrm{ug} / \mathrm{mL}$ & $2.76(<0.05-0.57)$ & $3.72(<0.05-0.57)$ & $3.30(<0.05-0.57)$ \\
\hline $\mathrm{IGF}-1, \mathrm{ng} / \mathrm{mL}$ & $150(35-232)$ & $142(35-232)$ & \\
\hline TSH, uUI/mL & & $2.7(0.70-4.17)$ & \\
\hline FT4, ng/dL & & $0.90(0.89-1.37)$ & \\
\hline Aldosterone, pg/mL & & $185(30-350)$ & $155.0(30-350)$ \\
\hline Active renin, $\mathrm{uU} / \mathrm{mL}$ & & $55(7-76)$ & $84(7-76)$ \\
\hline
\end{tabular}


testosterone $0.3(0.13-0.32) \mathrm{ng} / \mathrm{mL}$, LH $5.0(<12.0) \mathrm{mUI} / \mathrm{mL}$ and FSH $4.1(<9.6) \mathrm{mUI} / \mathrm{mL}$.

At 6 years and 4 months, the weight of the patient was $24.3 \mathrm{~kg}$ (0.98 SD) and her height was $119.8 \mathrm{~cm}$ (0.54 SD), with accelerated growth velocity (10.6 cm in 10 months). Hydrocortisone treatment at a dose of $5 \mathrm{mg} / \mathrm{m}^{2} /$ day was initiated. During her last visit at 6 years and 7 months, her weight was $25.3 \mathrm{~kg}(1.03 \mathrm{SD})$ and her height $121.3 \mathrm{~cm}(0.51$ SD). Laboratory work-up (Table 1) was performed, under hydrocortisone at a dose of $5 \mathrm{mg} / \mathrm{m}^{2} /$ day, although with irregular compliance. The need for treatment was reinforced in order to avoid complications.

\section{Discussion}

We described a new case of CAH due to 21-OH deficiency in a 6-year-old Portuguese girl with a mosaic form of Turner karyotype.

The first sign of virilization in our patient was premature pubarche at the age of 5 years. She was known to have a mosaicism TS, but only had a few TS stigmas and did not present with short stature. Laboratory investigation revealed elevated levels of 17-OHP and androgens, with normal sodium, potassium, FSH, LH, IGF1, cortisol, adrenocorticotropic hormone, active renin and aldosterone levels. As is strongly recommended, an SRY gene analysis was performed and this was negative. Continuing the investigation, the rare occurrence of coexisting $\mathrm{CAH}$ was investigated (2). Her elevated basal 17-OHP level and the CYP21A2 gene analysis (CYP21A2 genotype: c.[844G > T]; [CYP21A2del]) established a diagnosis of the non-classical form of $21-\mathrm{OH}$ deficiency. As her mother did not present with any genetic alterations, it is possible to infer that the complete deletion of CYP21A2 allele occurred de novo. The occurrence rate of de novo mutations in CYP21A2 alleles in affected patients with $21-\mathrm{OH}$ deficiency has been assessed to be $1-2 \%$. Her sister's genetic testing did not confirm nonclassical $\mathrm{CAH}$, although it also did not allow it to be ruled out completely.

This rare combination of TS and CAH was first described by del Arbol et al. (6) in 1983. So far, ten cases with both TS and CAH due to 21-OH deficiency have been reported in the literature $(1,2,3,5,6,7,8,9,10,11)$. Unlike most of the previously reported cases which were diagnosed as TS during the investigation of ambiguous genitalia or presented with concomitant diagnosis $(2,3,6,7,8,9,10)$, in our case, the diagnosis of TS was made initially. Only three cases known to have TS were later diagnosed as CAH $(1,5,11)$.
As in our patient, most of the previous cases had different degrees of virilism (2). Only one case of a 28-year-old woman who had decreased endometrial receptivity during IVF did not show virilism (1). Likewise, all cases described to date, except for one, had a mosaic Turner karyotype $(2,8)$.

The diagnosis of coexisting $\mathrm{CAH}$, particularly the nonclassical type, is difficult in patients with TS, as typical signs such as short stature, amenorrhea and hirsutism may be present in both diseases $(2,11)$. Furthermore, at an early age as in our case, it is even more difficult to detect coexisting $\mathrm{CAH}$, because some of these signs of both diseases, including short stature, have not yet manifested. Therefore, it is important to include genital examinations for virilization signs in routine visits in patients with TS (4), and to measure 17-OHP levels, especially in the presence of moderate-tosevere virilization (2).

The final heights of patients with concomitant TS and CAH tend to deteriorate due to both diseases (3). Unopposed hyperandrogenism caused by $\mathrm{CAH}$ may lead to initial skeletal maturation. However, it can mask the growth disorder, because premature closure of the growth plates leads to short final heights (2). In addition, insufficient hormone replacement therapy or overtreatment of $\mathrm{CAH}$ also causes final short stature (7). At the same time, TS can cause short stature. However, the prevalence of short stature in rare $45, \mathrm{X} / 47, \mathrm{XXX}$ mosaicism individuals is only $64.3 \%$, that is, much less frequent than in pure $45, \mathrm{X}$ monosomy (over $95 \%$ ) (12). Therefore, we think the patient's karyotype may lead to better growth. It has been speculated that this may be related to the presence of $47, \mathrm{XXX}$ cell lines, because the triple-X syndrome often presents with taller stature (12). Nevertheless, the final adult height is not guaranteed without growth hormone (GH) treatment (13).

While it is possible to achieve good results in CAH patients with regular follow-up and treatment, in TS, GH treatment initiated at supraphysiological doses and at an early age (before the age of 4 years) can lead to a considerable height gain, despite the absence of GH deficiency in TS $(7,11)$. In a previously case of a one-year-old patient with TS and $\mathrm{CAH}$, in addition to treatment with appropriate doses of glucocorticoids and mineralocorticoids, $\mathrm{GH}$ treatment was initiated when a slowing in growth was later observed (7). Our patient did not have short stature, probably due to accelerated skeletal maturation and some partial protection provided by her karyotype, as discussed previously. However, due to the coexistence of the two pathologies and irregular therapeutic compliance, her growth potential may be compromised. In our country, Portugal, GH treatment 
is approved for TS when there is a diagnosis confirmed by chromosomal analysis, chronological age $>2$ years, bone age $<12$ years before puberty, and height $<-2$ SD and $z$-score of the height velocity $<10^{\text {th }}$ percentile for 1 year. After improving our patient's compliance and adequately controlling her $\mathrm{CAH}$, we can question whether our patient will benefit from the earliest possible GH treatment, because her height may never be $<-2 \mathrm{SD}$, but growth may end too soon.

\section{Conclusion}

In conclusion, we presented a patient with the non-classical form of $\mathrm{CAH}$ due to 21-OH deficiency and mosaic TS, who presented with premature pubarche. To the best of our knowledge, this is the first report of this rare combination in a Portuguese patient. A review of the literature showed that this is the fourth case where the diagnosis of $\mathrm{CAH}$ was later than the diagnosis of TS. If signs of virilism are detected in patients with TS, rare coexisting CAH should be suspected in the absence of SRY.

\section{Ethics}

Informed Consent: Written informed consent was obtained from the mother.

Peer-review: Externally peer-reviewed.

\section{Author Contributions}

Surgical and Medical Practices: Joana Serra-Caetano, Rita Cardoso, Isabel Dinis, Alice Mirante, Concept: Isabel Inácio, Joana Serra-Caetano, Alice Mirante, Design: Isabel Inácio, Joana Serra-Caetano, Rita Cardoso, Alice Mirante, Data Collection or Processing: Isabel Inácio, Joana Serra-Caetano, Rita Cardoso, Analysis or Interpretation: Isabel Inácio, Joana Serra-Caetano, Rita Cardoso, Literature Search: Isabel Inácio, Writing: Isabel Inácio, Joana Serra-Caetano, Rita Cardoso, Isabel Dinis, Alice Mirante.

Financial Disclosure: The authors declared that this study received no financial support.

\section{References}

1. Cohen MA, Sauer MV, Lindheim SR. 21-hydroxylase deficiency and Turner's syndrome: a reason for diminished endometrial receptivity. Fertil Steril 1999;72:937-939.

2. Lee KF, Chan AO, Fok JM, Mak MW, Yu KC, Lee KM, Shek CC. Late presentation of simple virilising 21 -hydroxylase deficiency in a Chinese woman with Turner's syndrome. Hong Kong Med J 2013;19:268-271.

3. Maciel-Guerra AT, Guerra G Jr, Marini SH, Matias Baptista MT, Marques-de-Faria AP. Female pseudohermaphroditism due to classical 21-hydroxylase deficiency in a girl with Turner syndrome. Clin Genet 1997;51:351-353.

4. Onder A, Aycan Z, Cetinkaya S, Kendirci HN, Bas VN, Agladioglu SY. Assessment of the 21-hydroxylase deficiency and the adrenal functions in young females with Turner syndrome. J Pediatr Endocrinol Metab 2012;25:681-685.

5. Ságová I, Stančík M, Pavai D, Kantárová D, Vaňuga A, Vaňuga P. [Rare combination of Turner syndrome and congenital adrenal hyperplasia with 21-hydroxylase deficiency: case report]. VnitrLek 2018;64:432436.

6. del Arbol JL, Soto Más JA, Fernández-Abril JA, Raya Muñoz J, Martínez Tormo F, Gómez Rodríguez J, Gómez Capilla JA, Peña Yáñez A. Turner syndrome caused by deletion of the long arm of the $\mathrm{X}$ chromosome associated with adrenogenital syndrome caused by partial deficiency of 21-hydroxylase. Rev Clin Esp 1983;171:67-71.

7. Kendirci HN, Aycan Z, Çetinkaya S, Baș VN, Ağladıoğlu SY, Önder A. A Rare Combination: Congenital Adrenal Hyperplasia Due To 21 Hydroxylase Deficiency and Turner Syndrome. J Clin Res Pediatr Endocrinol 2012;4:213-215.

8. Larizza D MM, Cascone E, Daielle P, Cuccian M. A genetic and hormonal investigation of 21-hydroxylase deficiency in Turner's syndrome. In: Pintor C, Muller EE, Loche S, New MI (eds). Advances in paediatric endocrinology Berlin and Heidelberg: Pythagora Press, Milano \& Springer-Verlag, 1992;189-194.

9. Montemayor-Jauregui MC, Ulloa-Gregori AO, Flores-Briseño GA. Associated adrenogenital and Turner's syndrome mosaicism. Plast Reconstr Surg 1985;75:877-881

10. Rabbani B, Mahdieh N, Sayarifar F, Ashtiani MT, New M, Parsa A, Akbari MT, Rabbani A. A girl with 45,X/46,XX Turner syndrome and salt wasting form of congenital adrenal hyperplasia due to regulatory changes. Clin Lab 2012;58:1063-1066.

11. Atabek ME, Kurtoğlu S, Keskin M. Female pseudohermaphroditism due to classical 21-hydroxylase deficiency and insulin resistance in a girl with Turner syndrome. Turk J Pediatr 2005;47:176-179.

12. Tang $\mathrm{R}$, Lin L, Guo Z, Hou H, Yu Q. Ovarian reserve evaluation in a woman with 45,X/47,XXX mosaicism: A case report and a review of literature. Mol Genet Genomic Med 2019;7:e00732. Epub 2019 May 8

13. Yoo SH, Ahn MB, Kim SH, Cho WY, Jung MH, Suh BK, Cho K. A case of 45,X/47,XXX mosaic Turner syndrome: Clinical manifestations and effect of growth hormone treatment. J Genet Med 2020;17:47-50. 